\title{
Bulbous bow applications on a catamaran fishing vessel for improving performance
}

\author{
Samuel $^{1,2, *}$, Dong-Joon Kim ${ }^{1}$, Muhammad Iqbal $^{2}$, Aldias Bahatmaka $^{3}$ and Aditya Rio \\ Prabowo ${ }^{3}$ \\ ${ }^{1}$ Department of Naval Architecture and Marine Systems Engineering, Pukyong National University, \\ Republic of Korea \\ ${ }^{2}$ Department of Naval Architecture, Diponegoro University, Republic of Indonesia \\ ${ }^{3}$ Department of Interdisciplinary Program of Marine Design Convergence, Pukyong National \\ University, Republic of Korea
}

\begin{abstract}
This study aims to prove the usefulness of a bulbous bow traditional catamaran fishing vessel. Bulbous bow applications are widely used to reduce wave resistance. The fishing vessel resistance was calculated using CFD (Computational Fluid Dynamic) approach and combined with classical slender body theory. In this research, the application of bulbous bow was being adopted on traditional catamaran fishing vessel to reduce the total resistance. The bulbous bow has adopted based on Kracht method. Modeling procedure was developed by using linear form coefficients. The ship resistance was simulated using Tdyn software which basically Finite Element Method. The results show that adding bulbous bow can decrease or increase the ship's total resistance.
\end{abstract}

\section{Introduction}

The conversion of fishing vessels from monohull to catamaran form was carried out in 2015. The ship was launched using crane (fig. 1a). This conversion aims to increase the payload capacity up to 2 times since the ship has twin hull (fig. 1b). However, this conversion became bad news for the fishermen because the resistance of catamaran form increases up to almost four times compared to monohull form. Several studies on catamaran resistance have been conducted in the past, including earlier experiments by Everest, Oving, Pien [1]-[3] as well as a theoretical study Doctors [4]. Molland has generated the form factor of catamaran form which includes the interference factor as part of viscous resistance component [5]. Jamaluddin et al. has modified the Molland's form factor by adding S/L variable [6]. The calculation of ship resistance using Tdyn has been carried out by Samuel et al. [7] and Iqbal et al. [8] to estimate multihull ship resistance. Julio Garcia et al. using finite element method based on the finite calculus for analysis of free surface flow problems [9]. A bulbous bow that has been adopted widely in a monohull should only be fitted if it will reduce the ship resistance which its effect will increase the ship speed or reduce the fuel consumption [10]. Therefore, the main objective of this research is to

\footnotetext{
*Corresponding author: undip_samuel@yahoo.com
} 
develop catamaran ship resistance using a bulbous bow. This proposed method can generate the new shape of a bulbous bow. The ship resistance will be simulated using Tdyn software which is basically CFD approach.

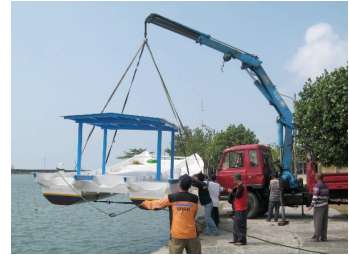

a

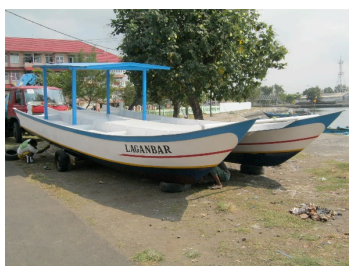

b

Fig. 1. Catamaran fishing vessel MV. Laganbar.

\section{Bulbous bow design}

The main function of the bulbous bow is to reduce resistance when the ship is operating. The bulbous bow shape affects the hydrodynamics of the velocity field around the bow, that is, on the rising wavelength of the ship, which is usually accompanied by a reduction of the wave resistance. By smoothing the flow around the body, the resistance will decrease.

Therefore, the addition of bulbous bow will be advantageous depending on the size, position, and shape of the bulbous bow. Generally, at low speeds, the effect of the bulb is negative. When the Froude Number increases, its effect becomes positive and increases up to a maximum value. In this study, Kracht's method was used to get an initial bulbous bow. Kracht [11] classified the bulbous bow types :

a. $\nabla$ - Type: The nabla-type also has a drop-shaped sectional area $\mathrm{A}_{\mathrm{BT}}$ (fig. 2c), but its center of the area is situated in the upper-half part, indicating a volume concentration near the free surface.

b. O - Type: This type (fig. 2b), with an oval sectional area $\mathrm{A}_{\mathrm{BT}}$ and a center of the area in the middle, has a central volumetric concentration.

c. $\Delta$ - Type: (fig. 2a) Shows the drop-shaped sectional area $\mathrm{A}_{\mathrm{BT}}$ of the delta type with the center area in the lower half part.

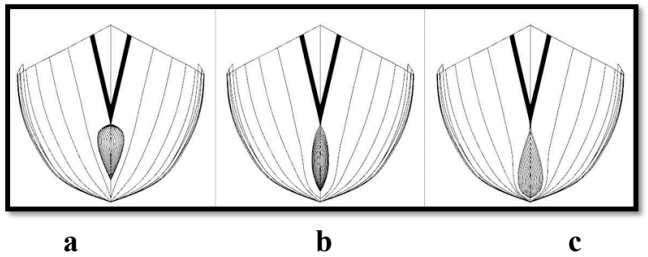

Fig. 2. Modeling bulbous bow section.

Kracht [11] has three linear bulb parameter :

a. The breadth parameter: the maximum breadth $B_{B}$ of the bulbous bow sectional area at the $\mathrm{FP}$ is divided by the beam $\mathrm{B}_{\mathrm{MS}}$ of the ship, which is denoted by $\mathrm{C}_{\mathrm{BB}}\left(\mathrm{C}_{\mathrm{BB}}=\mathrm{B}_{\mathrm{B}} / \mathrm{B}_{\mathrm{MS}}\right)$

b. The length parameter: the bulbous bow length $\mathrm{L}_{\mathrm{PR}}$ is divided by the $\mathrm{L}_{\mathrm{PP}}$ of the ship; it is denoted by $\mathrm{C}_{\mathrm{LPR}}\left(\mathrm{C}_{\mathrm{LPR}}=\mathrm{L}_{\mathrm{PR}} / \mathrm{L}_{\mathrm{WL}}\right)$

c. The depth parameter: the height $Z_{B}$ of the bulbous bow tip is divided by the draft $T_{F P}$ at the FP; it is denoted by $\mathrm{C}_{\mathrm{ZB}}\left(\mathrm{C}_{\mathrm{ZB}}=\mathrm{Z}_{\mathrm{B}} / \mathrm{T}_{\mathrm{FP}}\right)$

3D modeling of the bulbous bow is assisted using Rhinoceros software. The solid model generated from multiple curves and surface. The linear bulb ratio of the Kracht parameter is 
used to obtain an initial bulbous form. The definition of the parameters of the linear coefficients can be seen in fig. 3. The purpose of this research to make a bulbous bow shape with type $\Delta$-Type, O-Type, and $\nabla$-Type. In this study, using variable $\mathrm{Zb}$ to produce the desired bulbous bow shape, while at $\mathrm{L}_{\mathrm{PR}}$ and $\mathrm{B}_{\mathrm{B}}$ become fixed variable. Comparison of $\mathrm{L}_{\mathrm{PR}} / \mathrm{LPP}=0.018 ; \mathrm{B}_{\mathrm{B}} / \mathrm{B}=0.170$ and $\mathrm{Zb} / \mathrm{draft}=0.274 ; 0.572 ; 0.838$ as shown in fig. 2 . This model that uses the parameter scenario will generate the shape $\Delta$-Type, O-Type, and $\nabla$ Type.

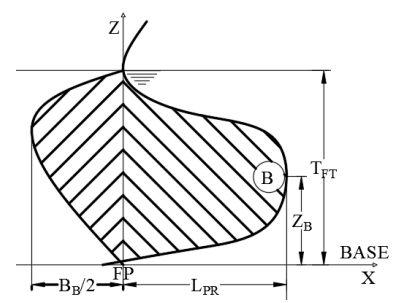

Fig. 3. Linear bulb quantities.

\section{Methodology}

The subject of this study is a traditional catamaran fishing vessel, the main dimensions measure obtained from the results of the direct measurement, which was modified by fishermen. The main dimensions result are presented in table 1 . The slender body method was applied for the calculation of monohull and multihull hull resistance, assuming a thin hull where the ratio between the length and width of the large vessel (L/V1/3> 4.0). The slender body method is based on Michell's theory approach [12] which expresses the wave resistance of the thin wall of the hull and was developed by Couser [13]. The effects of resistance due to spray and wave-breaking cannot be calculated properly [14]. Therefore, The viscous resistance was calculated based on the skin friction formula ITTC'57, and then the calculation of form factor $(1+\beta \mathrm{k})$ for catamaran using the empirical formula given by Molland and Jamaluddin [6],[15]. This is because Michell's theory has not been able to calculate breaking-waves and wave interference. Insel and Molland [16] proposed that the total resistance of a catamaran expressed by :

$$
\mathrm{CT}_{\mathrm{CAT}}=(1+\beta \mathrm{K}) \mathrm{CF}+\tau \mathrm{CW}
$$

Where $\mathrm{CT}_{\mathrm{CAT}}$ is the total resistance coefficient; $(1+\beta \mathrm{K})$ is the hull form coefficient; $\mathrm{CF}$ is the frictional resistance coefficient; $\tau$ is the wave interference factor and $\mathrm{CW}$ is the wave resistance coefficient.

Table 1. Main dimensions of traditional catamaran fishing vessel MV. Laganbar.

\begin{tabular}{|c|c|}
\hline Length of waterline (LWL) & $8.72 \mathrm{~m}$ \\
\hline Draft (T) & $0.50 \mathrm{~m}$ \\
\hline Beam demi hull (B) & $1.01 \mathrm{~m}$ \\
\hline Beam overall (BOA) & $2.88 \mathrm{~m}$ \\
\hline
\end{tabular}


Then, Jamaluddin et al. modified hull form coefficient by considering $\mathrm{S} / \mathrm{L}$ effect, can be calculated from equation 2 .

$$
(1+\beta \mathrm{k})=3.03\left(\mathrm{~L} / \mathrm{V}^{1 / 3}\right)^{-0.40}+0.016(\mathrm{~S} / \mathrm{L})^{-0.65}
$$

The value of $\tau$ is the wave interference factor caused by the fluid flow around the catamaran at a certain distance (S) of the ship length (L). The resistance component of catamarans has a more complex phenomenon than a monohull, caused by the influence of the interaction between the two-ship's hull and the interference wave. Which gives effect to the formation of the boundary layer and the longitudinal vortices. While the wave interference due to the interaction of waves generated by each catamaran hull. That is difficult to predict the total resistance of the catamaran vessel, this study is assisted by Tdyn.

Tdyn software is simulation program, which capable to compute the resistance of ship by potential flow method, boundary layer method and Reynold Average Navier-Stokes (RANS). The total resistance was calculated in every element based on finite element method. The analysis was carried out with computer code SHYNE, based on the algorithm and pre/post processor GID developed at CIMNE. CFD formulation presented can be found in Tdyn [17].

The NURBS definition is shown in fig. $4 b$, nonuniform rational B-splines (NURBS) are mathematical representations of $2 \mathrm{D}$ or $3 \mathrm{D}$ objects, NURBS can generate curves and surfaces to make 3D modeling.

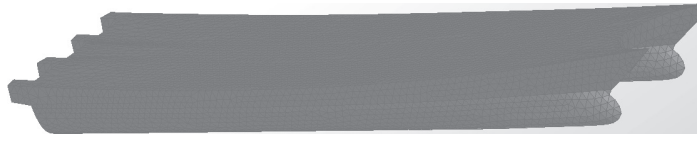

a

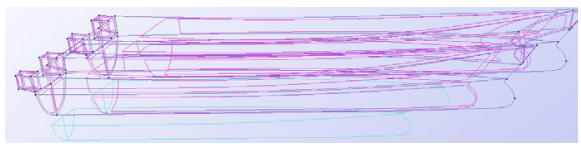

b

Fig. 4. Geometrical definitions.

The computation domain is discretized using an unstructured surface mesh grid. The mesh around the catamaran consists of about 140.130 tetrahedra and 39.610 triangle elements distributed. The surface mesh catamaran used in the analysis is presented in fig. $4 \mathrm{a}$.

\section{Results and discussions}

The total resistance of a catamaran can be calculated using equation 1-2. It was validated using a combination of calculations, the empirical formula, and slender body. The result of numerical computation and Jamaluddin's formula shows that the total catamaran resistance value does not exceed the $5 \%$ error, as shown in fig. 5. Interference of wave resistance between two catamaran hulls can be contribute negative or positive as presented from the theoretical and experimental results.

The fisherman modified a monohull form to a catamaran with the $\mathrm{S} / \mathrm{L}$ ratio being 0.2 , that modification can increase the payload capacity up to two times with the same draft. In fig. 6 shows the total catamaran resistance and two times the monohull.

The comparison of resistance between original catamaran and catamaran with a bulbous bow was presented in fig. 7. Total resistance catamaran based on Froude number used in the Jamaluddin's formula, i.e. the Froude number 0.28-0.65. The reason to use the same Froude number is to simplify and to reduce errors in the calculations performed.

The nabla-type form has the lowest resistance at fr 0.47 , but at Fr 0.65 is relatively larger than the other. At low speed, the bulbous bow will give bad impact, but at high speed, will have a good effect. The applications of the bulbous bow are complicated to 
apply at several speeds, this is because each bulb has different characteristics. However, the naval architect may choose the bulb which used at service speed.

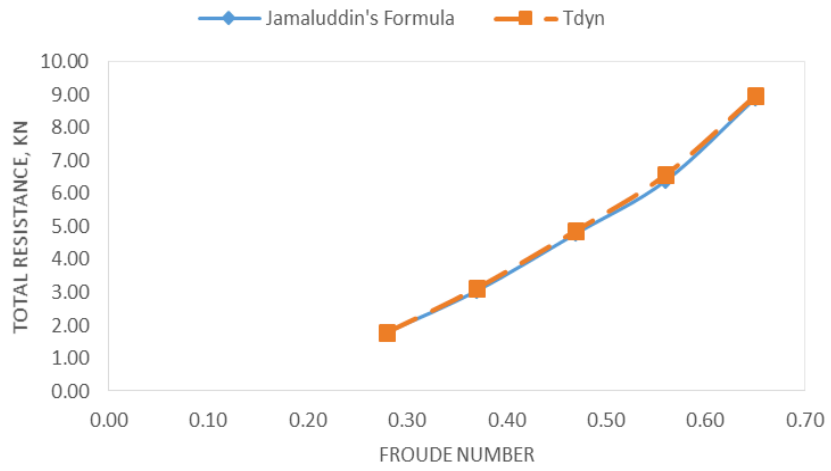

Fig. 5. Comparison of resistance numerical results with Jamaluddin's formula.

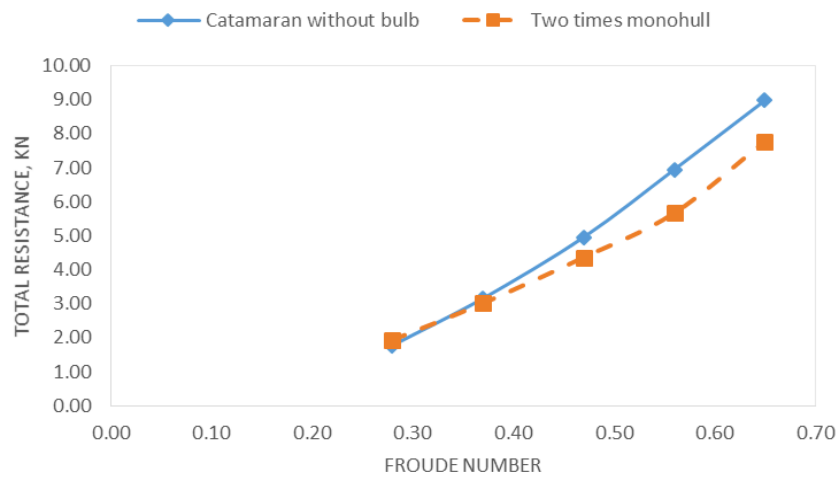

Fig. 6. Comparison of catamaran resistance.

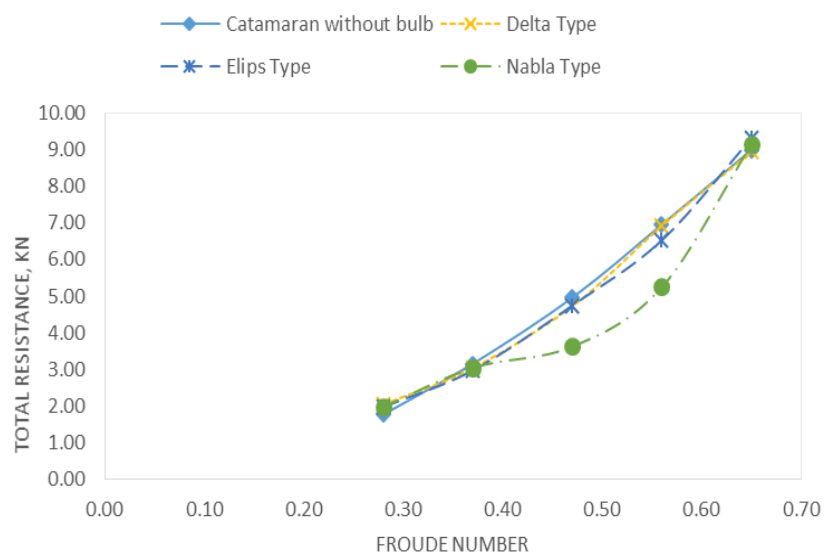

Fig. 7. Result of resistance

\section{Conclusion}

Efforts to improve ship performance vary widely, one of which is to add a bulbous bow with several parameters. This effort was successfully done by using three forms of a 
bulbous bow. Nabla type was selected as the most influential bulbous bow to be applied on a traditional catamaran boat. Nabla type can reduce the resistance by an average of $10 \%$. At low speeds, the bulbous bow has no significant effect. However, at high speed, its effect becomes positive and increases up to a maximum value.

The authors wished to thank the Ministry of Oceans and Fisheries Korea for funding this research under the scheme 'Next Generation Korea-model Fishing Vessel Development \& Test-bed Application' and Indonesia Ministry of Finance Lembaga Pengelolaan Dana Pendidikan (LPDP).

\section{References}

1. J. T. Everest, Some research on the hydrodynamics of catamarans and multi-hulled vessels. North East Coast Inst. Eng. Shipbuild. (1968).

2. P. C Pien, Int. Semin. wave Resist. Soc. Nav. Archit. Japan (1976).

3. A. J. Oving, Resistance prediction method for semi planing catamarans with symmetrical demihulls. (1985).

4. L. J. Doctors, J. Eng. Australia 4, 295-302 (1991).

5. A. F. Molland, P. A. Wilson, D. J. Taunton, S. Chandraprabha \& P. A. Ghani, The Int. J. of Maritime Eng 146, 19-38 (2004).

6. A. Jamaludin, I. K. A. P. Utama, B. Widodo \& A. F. Molland, J. of Eng. for the Maritime Env. 227, 51-60 (2012).

7. Samuel, M. Iqbal \& I. K. A. P. Utama, Int. J. of Tech 6, 432-441 (2015).

8. M. Iqbal, Samuel, Int. J. of Tech 8, 85-91 (2017).

9. J. Garcia, A. Valls \& E. Oñate, Int. J. for Num. Methods in Eng 76, 1297-1327 (2008).

10. D. Chrismianto, \& D. J. Kim, J. of Marine Sci. and Tech 19, 479-492 (2014).

11. A. M. Kracht, SNAME Trans 86, 197-217 (1978).

12. J. H. Michell, Phil. Magazine 5, 106-123 (1989).

13. P. R. Couser, J. F. Wellicome \& A. F. Molland, Inter. Shipbuilding Prog 45, 444 (1998).

14. Murdijanto, I. K. A. P. Utama \& A. Jamaluddin, Makara Seri Teknologi 15, 25-30 (2011).

15. A. F. Molland, J. F. Wellicome \& P. R. Couser, Trans. RINA 138, 59-71 (1996).

16. M. Insel \& A. F. Molland, The RINA 134, 1-11 (1991).

17. Tdyn. in Tdyn Theory Manual 1-33 (2014). 